\title{
The Relationship between Self-Belief, Belief in Continuity, Self-Blame, Stability, Mysterious Pain and Intensity of Chronic Pain Disorder
}

\author{
Mohammad Kianbakht $^{1}$, Ghasem Ansarinia ${ }^{2}$, Shiva Nematpour kapourchal $^{3}$
}

\section{ABSTRACT}

Object (s): the present research has considered the relationship between beliefs, perceptions of pain with intensity of chronic pain disorder. Methods: these fire fighters of the city of 504 research is known as sectional study. In such a study, Tehran was selected by cluster sampling. Data from the questionnaires, chronic pain, pain beliefs and formed perceptions, coping strategies and perfectionism were collected. Data is analyzed by the step by step method which is called regression analyses method. Results: there was positive significant relation between beliefs in continuous pain in the future, belief in self-blame, belief in pain stability at the present, belief in mysterious pain with the intensity of chronic pain disorder as well as, according to the multiple variable of regression analyses, the results has been showed that, the contribution of each pre-variable, self-blame $21 \%$ continuous pain, $84 \%$ separately is as follow; Mysterious pain; as well as the various intensity of pain disorder was $1.3 \%$, pain stability $8.7 \%$ explained too. Conclusion: Regard with result of this study, it is essential to create self-adaptive belief in the patients who suffer from chronic pain, so if we use the treatment of self-adaptive cognition along with other treatments to reduce pain, it can have more benefit to control and reduce the chronic pain among the firemen who suffer from it.

Keywords: belief in continuity, self-blame, stability and mysterious pain, chronic pain.

Chronic pain is a pain that often(not always)accompanied with an injury, but by the loss of the main factors that cause pain, it will remain for a long time and it is not possible to explain it with a principal pathology and often the interventions of mental health is rarely effective(Turk and Okfuji, 2001).

${ }^{1} \mathrm{Ph} . \mathrm{D}$ Student Of Clinical Psychology, Department Of Psychology, Aligarh Muslim University, India.

${ }^{2}$ Ph.D Student Of Clinical Psychology, Department Of Psychology, Aligarh Muslim University, India.

${ }^{3}$ Clinical Psychologist In Nor Clinic, Tehran, Iran.

(C) 2015 I M Kianbakht, G Ansarinia, S Nematpour; licensee IJIP. This is an Open Access Research distributed under the terms of the Creative Commons Attribution License (http://creativecommons.org/licenses/by/2.0), which permits unrestricted use, distribution, and reproduction in any Medium, provided the original work is properly cited. 


\section{The Relationship between Self-Belief, Belief in Continuity, Self-Blame, Stability, Mysterious Pain and Intensity of Chronic Pain Disorder}

The different between chronic pain and acute pain is a contract of ( 3 to 6 months) and it will be defined based on this idea whether the pain is more than the expected time(Turk and Okfuji, 2001). Chronic pain is nothing but a physical sign. Patient activity, along continuing pain will be decreased and this phenomenon in return creates depression and physical de conditioning. Our understanding of chronic pain and our approach is increasingly complex. The patient with chronic pain could be cured by a pain-killer in the recent years, but we know that nowadays these medicines are not sufficient, especially when the pain will affect the different aspects of an individual like family, job, sleeping, and amusement. This issue is right; it means everything that contains all quality of life. New approaches to the treatment of chronic pain usually involve dealing with many or all of these areas, as well as pain held(Nicholas, Molloy, Tonkin and Beeston, 2004). Related beliefs about pain are the set to be interpreted in the light of the pain(Lazarus and Folkman, 1981).Beliefs are the cognitive configuration which is formed individually or it may culturally shared between individuals. Pain beliefs get shape duration of life by knowledge and experiences and it covers all pains in an individual. The evaluation and beliefs of pain can deeply affect the emotional and behavioral responses to the pain; the patients continue treatment for getting free of pain, but the failure of therapeutic efforts that merely aims to eliminate facial pain causes increasing hopelessness and depression in patient. However, Aggravated depression may loss his chore interest. This phenomena itself reduces physical fitness, moreover, when the patients continue Deficient treatment it may stop the patients of being encouraged to the treatment and the patient has no any role in such a treatments, these destructive thoughts and believes in patients reinforced by an insufficient treatment, some of medicines(anti-depression, pain-killers and etc) will create more problem in patients and these medicines have side effects, the patient may loses the job and socio economic problem and family of patient also suffering because of the patient with chronic pain. In summary, the pain can affect each part of life of an individual who is challenging with pain. Chronic pain is caused by active disease processes, tissue damage, and other insults to our body. Rheumatoid arthritis, cancer, musculoskeletal problems, cardiac disease and headache are but a few of the conditions that can lead to chronic pain. Many people suffer from chronic pain for which the underlying cause is unknown or the level of their suffering considered in excess of identified pathology or disease process (Turk and Monaarch, 2001).

\section{METHODOLOGY}

In this research a descriptive analysis of chronic pain patients performed, the Statistical research community were selected from all firefighters in the city of Tehran which 504 members were selected randomly in a cluster design in several steps. in the first step with the method of cluster offices of governmental organization in four areas, north, east, west, south of Tehran were divided and two area were selected randomly to be ready for the research, in the next level again in a clustering method, 35 offices were selected in a statistical sampling method with the possibility of choosing. Average and standard deviation age of all male staffs were 31/85 and 6/93, also 77/3 percent of staffs were married and 22/7 unmarried. Among the investigated sample 4 percent had the severity of chronic pain disorder type one, and 3 percent had the severity of chronic pain disorder type 2, and 25/2 percent had the severity of chronic pain disorder type 3 , and 67/9 percent had no any problem with the relation of severity of chronic pain? 


\section{TOOLS USED}

\section{PBPI=Pain Beliefs and Perception Inventory}

PBPI is a 4-subscale questionnaire that explores a patient's personal beliefs in their subjective experience of pain The pain beliefs and perception inventory(PBPI) is a widely used instrument for assessing pain beliefs, the PBPI was designed to assess the representation and the meanings patients hold regarding pain. The initial version of the PBPI consisted of 16 items grouping into three subscales;(1) time; (2) mystery and (3) self-blame. The PBPI consist of 16 items assessing four dimensions of pain beliefs;(1) the Mystery dimension (4 items) measures the belief that pain is mysterious and is a poorly understood experience (2)the permanence dimension(5items) assesses the belief that pain is an enduring part of life: the constancy dimension(4items) measures the temporal dimension of daily pain: and (4) the self blame dimension(3items) taps patient's beliefs that they themselves are responsible for their own experience of pain. The four scales possessed satisfactory internal consistency (Cronbach as;0.64-0.83). Patients are asked to rate using a 4-point Likert scale $(-2=$ strongly disagree, $-1=$ disagree, $+1=$ Agree, $+2=$ strongly agree) their level of agreement with each of 16 statements about beliefs and perceptions concerning pain. Pain beliefs are defined as 'patients' own conceptualization of what pain is and what pain means for them (Williams and Thorn, 1989). The main dimensions of these beliefs are eventuality of pain lifting, the mysterious nature of pain, wonder at the cause of pain, lifestyle altering because of pain, possibility of personal control over pain, blame, and constant vs intermittent nature of pain experience. A useful tool to assess pain beliefs is the Pain Beliefs and Perceptions Inventory (PBPI), a 16-question Likert-type scale addressing 4 dimensions of pain beliefs: seeing pain as mysterious (Mystery), holding oneself responsible for pain (Self Blame), regarding one's condition as lingering in the future (Permanence), and/or continuous over time (Constancy). PBPI was initially designed around 3 main cores, the dimensions Mystery, SelfBlame and Time, but the Australian and German replication of the scale showed an improvement in the method by adding a fourth dimension (Constancy and Permanence instead of Time) (DeGood and Tait, 2001, Asghari, Karim and Amarlou, 2006).This change provided a further tool to explore disorders not associates with intermittent pain, like headache, in which is likely that Constancy and Permanence are regarded differently by patients. 8 In this new version, PBPI was validated in the United States by its developers, 9 in England, 8 in Norway, 10 in France, 11 in China, 12 and in Italy.13 It is worth noting that it is not possible to define a score of normality for PBPI subscales, because mental representations can never be regarded as pathological in themselves. PBPI has been used to assess pain beliefs in heterogeneous samples of patients suffering from chronic back, limbs, head, and abdominal pain.8,9,11 in these studies, beliefs that pain would be enduring and constant are associated with increased reported pain intensity, regardless of actual pain duration.1,9,12 Chronic patients create a mental representation of pain as persistent and mysterious, with high scores in Permanence and Mystery scales of PBPI, which in turn is related to more catastrophizing and worse coping and disability.3,7,14 a correlation has also been found between pain beliefs of permanence, mystery and self-blame and psychological distress, often displayed with anxiety and depression symptoms. The factorial structure, 


\section{The Relationship between Self-Belief, Belief in Continuity, Self-Blame, Stability, Mysterious Pain and Intensity of Chronic Pain Disorder}

reliability, and validity of the Pain Beliefs and Perceptions Inventory (PBPI) were investigated in a sample of 84 pain patients drawn from a pain clinic in the United Kingdom. The recovered factorial structure replicated that of a previous study. The 4 derived subscales, mysteriousness, Self-Blame, Pain Constancy and Pain Permanence, had excellent reliability (internal consistency); Chronbach's alpha was greater than 0.80 .

\section{Chronic pain Questionnaire}

In this study we used the chronic pain questionnaire for measuring chronic pain, this questionnaire first introduced by (Von Korff, Dworkin and Leresch, 1990, Von Korff, Ormel, Keefe and Dworkin, 1992), and in Iran it is modified by (AsghariMoghadam,2011), this questionnaire was used in several studies on patients with chronic pain in Iran.This questionnaire has been made in biopsychosocial approach(AsghariMoghadam,2011).This test has 75 material and it measures the different dimension of chronic pain, the six first questions check the individual identity and cognition, but the remain tests demonstrate about chronic pain, average of severity of pain, disability and the average of disability, the number of days that an individual is on leave due to pain, in duration of 6 months before, it causes to find the different level of chronic pain between individuals, also the onset of pain, the impact of pain on social interaction and family .and it gives a comprehensive information about chronic pain and the condition of an individual, chronic pain disorder scale has advantages, in Epidemiology studies, it makes the study easier to separate and category the individuals with severity of pain disorder, a studies revealed that those individuals who report the chronic pain just a few of them are disabled due to pain(Von Korff, Dworkin and Leresch, 1990).According to(Von Korff, Ormel, Keefe and Dworkin, 1992). The categorical lever of chronic pain includes:

1) Categorizing chronic pain and it is match with the severity of chronic pain and each category is independent of the other category.

2) It has an easy scoring thus; the clinical usage is easy as well.

3) It can give an exact measurement of patients with chronic pain.

4) It is not depend on the location and the cause of pain rather we can use it in all patients with chronic pain.

Scoring and interpretation of result is easy and it is able to distinguish the five groups with different chronic pain, zero; without problem one: weak disability, severity of weak pain, two; weak disability, high pain, three: severe disability, severe limitation, some of areas of test are calibrated on 10 point scale that zero number shows nothing and 10 shows the maximum, In this study criteria for recognition were measured by the questions number 16,17;(AsghariMoghadam M A.2011).Including: experiencing pain in duration of past 6 months, Continuing pain in duration of past 6 months(score higher than 3),severity of pain: sum of the numbers 19,20,21 that patient has chosen, then dividing the answer by three and the result multiplied by 10 , severe disability: outcome summation of the questions 46,50,53, that patient answered is dividing by 3 
and multiplying the result into 10 . This number will be equivalent with the help of table number 1. And the answer of question number 26 will be equivalent by the help of table number 2 that it is necessary to determine the severity of chronic pain, summation of the equivalent number of severe disability and the number of absence days in job. This questionnaire has been used in different studies related to chronic pain in Iran and the coefficient of reliability of the test results is desirable in various researches, for instance (Asghari, Karami and Rezai, 2002), the statistical results showed that the questionnaire has satisfactory internal consistency.(Alpha coefficient of Cronbach) and the obtained for the whole scale was 0.88 Cronbach's alpha ranging.

Table 1: the severity of disability

\begin{tabular}{|l|l|}
\hline \multicolumn{2}{|l|}{ score of disability } \\
\hline The patient's score of disability & Equivalent \\
\hline $0-29$ & 0 \\
\hline $30-49$ & 1 \\
\hline $50-69$ & 2 \\
\hline 70 and more & 3 \\
\hline
\end{tabular}

Table 2: the number of days of absence from work

\begin{tabular}{|r|r|}
\hline $\begin{array}{r}\text { Equivalent } \\
\text { number }\end{array}$ & number of absent days \\
\hline $0-6$ days & 0 \\
\hline $7-14$ days & 1 \\
\hline $15-30$ days & 2 \\
\hline 31 and more & 3 \\
\hline
\end{tabular}

Table 3: Classification of chronic pain disorder

\begin{tabular}{|l|l|}
\hline Characteristic & category \\
\hline $\begin{array}{l}\text { From the past } 6 \text { months, there was no problem with } \\
\text { chronic pain }\end{array}$ & without problem \\
\hline $\begin{array}{l}\text { The severity of pain less than 50, disability score } \\
\text { less than 3 }\end{array}$ & level 1, light disability, light pain intensity \\
\hline $\begin{array}{l}\text { Severity of pain 50 or more, disability score less } \\
\text { than } 3\end{array}$ & level2, light disability, high pain intensity \\
\hline Disability score 3 to 4 , irrespective of pain intensity & level3, sever disability, average limitation \\
\hline Disability score 5 to 6, irrespective of & level4, sever disability, sever limitation \\
\hline
\end{tabular}




\section{DATA COLLECTION}

After the prior permission of the governmental head office authorities in Tehran city, data was collected through cluster random sampling in different offices separately, all subjects filled chronic pain questionnaire and PBPI=Pain Beliefs and Perception Inventory without any time limitation. After collecting the data, it was analyzed through SPSS version 16.0.

\section{RESULTS}

there was positive significant relation between belief in continuity pain in the future, belief in self-blame, belief in pain stability at the present, belief in mysterious pain with the intensity of chronic pain disorder as well as, according to the multivariate regression analyses, the results has been showed that (Table 4), the contribution of each pre-variable separately is as follow; Mysterious pain; $\% 48,(\mathrm{~F}=1,403=376 / 310, \quad \mathrm{P}<0 / 001)$. Continuous pain \%12, $(\mathrm{F}=1,402=122 / 317, \mathrm{P}<0 / 001)$.Self-blame \% 7.8, $(\mathrm{F}=1,401=98 / 749, \mathrm{P}<0 / 001)$. Pain stability.$\% 3.1$, $(\mathrm{F}=1 / 400=43 / 358, \mathrm{P}<0 / 001)$. In brief; the higher the intensity of chronic pain disorder was associated with higher pain beliefs. As well as the various intensity of pain disorder was explained too.

Table 4; Summary of multivariate regression stepwise model predictive variables intensity of pain disorder (pain beliefs)

\begin{tabular}{|l|l|l|l|l|l|}
\hline MODEL & $\mathbf{R}^{*}$ & $\mathbf{R S} * *$ & $\mathbf{A R S}^{* * *}$ & $\mathbf{S E E}^{* * * * *}$ & $\mathbf{R}^{2 * * * * *}$ \\
\hline $\mathbf{1}$ & .695 & .483 & .482 & $19 / 2977$ & $0 / 483$ \\
\hline $\mathbf{2}$ & .777 & .604 & .602 & $16 / 9185$ & $0 / 121$ \\
\hline $\mathbf{3}$ & .826 & .682 & .680 & $15 / 1740$ & $0 / 078$ \\
\hline $\mathbf{4}$ & .844 & .713 & .710 & $14 / 430$ & $0 / 031$ \\
\hline
\end{tabular}

*CORRELATION

$* * \mathrm{R}$ Square

***Adjusted R Square

$* * * *$ Std. Error of the Estimate

$* * * * * \mathrm{R}$ square change

According to table 5 it shows that the variable of mysterious pain has a great contribution in prediction of intensity of chronic pain disorder, $(\mathrm{Beta}=. / 38)$, however, other predictor variables like(Continuous pain in the future, self blame pain, continuity of pain at present with the betas, 0/26, 0/27, 0/21)has a significant affect also. 
The Relationship between Self-Belief, Belief in Continuity, Self-Blame, Stability, Mysterious Pain and Intensity of Chronic Pain Disorder

Table 5; Summary of multivariate regression stepwise model predictive variables intensity of pain disorder (pain beliefs)

\begin{tabular}{|l|l|l|l|l|l|l|}
\hline criteria & variable & B & Std.Error & Beta & t & Sig. \\
\hline $\begin{array}{l}\text { intensity of chronic } \\
\text { pain }\end{array}$ & Last step & & & & & \\
\hline & mysterious & $6 / 342$ & $0 / 522$ & $0 / 388$ & $12 / 139$ & $0 / 000$ \\
\hline & $\begin{array}{l}\text { continues } \\
\text { pain }\end{array}$ & $3 / 078$ & $0 / 378$ & $0 / 263$ & $8 / 142$ & $0 / 000$ \\
\hline & self-blame & $3 / 201$ & $0 / 358$ & $0 / 274$ & $8 / 937$ & $0 / 000$ \\
\hline & stability & $2 / 044$ & $0 / 310$ & $9 / 209$ & $6 / 585$ & $0 / 000$ \\
\hline
\end{tabular}

\section{RESULT AND DISCUSSION}

The primary aim of this study was to investigate the relationship between beliefs and formed perceptions of chronic pain disorders, Baseline results from the study indicated a high positive relationship between beliefs in pain with the intensity of chronic pain disorder $(\mathrm{p}<0 / 001)$ this result also show that beliefs in pain mystery is (48\%), believe in the relation of continuity in future $(12 \%)$, self blame $(\% 7 / 8)$, and belief in the stability of the pain (\%3/1), are able to predict the intensity of the chronic pain. However, it can be concluded the highest the pain beliefs, the more understanding of chronic pain disorder, the important beliefs in pan is a successive adjustment to the pain that has been shown in different studies(Williams and Thorn, 1986, Turner, Jensen and Romano, 2000, Forman, Herbert, Moitra, Yeomans and Geler, 2007, Asghari, Karim and Amarlou, 2006, Mohammadi, Dehghani, Heidari, Sedaght and Khatibi, 2013). According to different studies this issue is perceived that belief in pain will be acquired during the knowledge and experiences in life and it covers all area of an individual's experiences, beliefs and measurement of pain can deeply effect the behavior and emotional on an individual in response to pain, If pain symptoms are interpreted as a malicious threat and believe that the pain is more severe tissue damage then individual will react to the pain with a high intensity, and the individual also shows escape and avoidance behaviors, believe in pain and evaluating of pain are the main factors for and individual adjustment to the chronic pain disorder (Turner, Jensen and Romano, 2000). The results of this study provide empirical evidence for the importance of the biopsychosocial and important point to understand the nature of chronic pain and controlling pain in people with chronic pain. Some limitations of this study are to generalize the results met with caution. In the present study in order to assess research variables, we used pencil and paper, regarding to the limitation of tools like questionnaire to assess exact behavioral issues, the present study has a limitation. Present study is on a governmental organization staffs, and the caution should be taken, it is recommended to do such a research in different population, alternatively, analysis was carried out to teach hypotheses are derived from data from a crosssectional study. So any causal inferences from existing evidence are not permitted, it is recommended that future research plans or longitudinal experimental is possible to derive a 
causal relationship between psychological factors and create adaptive beliefs about intensity of chronic pain.

\section{REFERENCES}

AsghariMoghadam M A. (2011). Pain and its assessment, Explore new approaches to the psychology of pain.Roshd Publication. Tehran.

Asghari A, Karami B, Rezai S,.(2002). The prevalence of pain and chronic pain in both Elam and Qorveh.Journal of Psychology.6: 30-5.

Asghari A, Karim M N, Amarlou P. (2006). The role of beliefs about pain on coping with cancer pain.DaneshvarRaftar. 13: 1-22.

DeGood, DE, Tait RC. (2001). Assessment of pain beliefs and pain coping. In: Turk DC, Melzack R (Eds.) Handbook of pain Assessment, Second Edition. New York: Guilford Press. (pp. 310-312).

Forman, E.M, Herbert, J.D, Moitra, E, Yeomans, p. D, Geler, P.A. (2007). A randomized controlled effectiveness trial of acceptance and commitment therapy and cognitive therapy for anxiety and depression.Behaviour Modification.31 : 111-188.

Lazarus, R. S., \&Folkman. (1981). Coping and adaptation In W. D. Gentry (Ed.), Hand book behavioral medicine New York: Guilford press. (pp.: 91-111).

Mohammadi S, Dehghani M, Heidari M, Sedaght M, Khatibi A,. (2013). Explore Psychological similarities in patients with chronic pain and pain associated with muscle - Bones and their spouses. Journal of Behavioral Sciences. 23 (57).

Nicholas, Michael; Molloy, Allan; Tonkin, Lois; Beeston, Lee. (2004). Manage Your Pain. Translation By: Dr. Dehghani, Mohsen. Roshd Publication, (2007).

Turk DC \&Monaarch ES. (2001). Biopsychsocial perspective on chronic pain. In: DC, Turk and RJ, Gatchel, Eds, psychological Approaches to pain Management, Second edition new. York: Guilford. (2001). Pp. 3-18.

Turk, D. C., Okfuji, A. (2001).Pain terms and taxonomies of pain. In J. D. Loeser, S. H. Butler, C. R. Chapman, \& D. C. Turk (Eds.). Bonica's management of pain Philadelphia: Lippincott, Williams and Wilkins.(3rd ed., pp. 11-12).

Turner JA, Jensen MP, Romano JM. (2000). Do beliefs, coping, and catastrophizing independently predict functioning in patients with chronic pain? Pain.92: 112-112.

Von Korff M, Dworkin SF, Leresch. L. (1990).Graded chronic pain status: an epidemiologic evaluation.Pain.50, 113-130.

Von Korff M, Ormel J, Keefe FJ, Dworkin SF. (1992). Grading the severity of chronic pain. Pain, 40; 033-53.

Williams, D. A., \& Thorn, B. E. (1986). Can research methodology affect treatment outcome? A comparison of two cold press or test paradigms.Cognitive Therapy and research.10, $238-211$.

Williams, D. A., \& Thorn, B. E. (1989). An empirical assessment of pain beliefs. Pain, 31, $321-329$. 